\title{
Los medios digitales en Canarias: una forma de comunicar que se impone a los canales tradicionales
}

\section{Digital media in the Canary Islands: a way of communicating that is imposed on traditional channels}

\author{
Araceli ÁLVAREZ DÍAZ \\ Universidad de La Laguna (España) \\ aracelitfe@terra.com
}

Recibido: 31 de agosto 2013 Aceptado y Publicado: 4 de octubre de 2013

\section{Resumen}

Un espacio fragmentado como es el Archipiélago Canario cuenta en la actualidad con un amplio número de publicaciones diarias digitales de carácter informativo que han surgido en los últimos años con el objetivo de hacer llegar a la audiencia a través de Internet lo que ocurre en cada una de las islas. Determinar cuáles son sus contenidos, la distribución de las informaciones, su línea editorial y el número de sus lectores es el objetivo de este estudio.

\section{Abstract}

A space is fragmented as the Canary Islands now has a large number of digital dailies for information that have emerged in recent years in order to reach the Internet audience through what happens in each of islands. Identify their contents, distribution of information, their editorial and the number of readers is the goal of this study. 
Palabras Clave: Nuevo periodismo, Enfoques, Audiencias, Temática, Ámbito geográfico Key Words: New journalism, Approaches, Audiences, Theme, Geographical context.

\section{Introducción}

El uso cada vez más frecuente de las nuevas tecnologías y el acceso masivo a una herramienta de trabajo que día a día se hace más imprescindible como es la Internet han propiciado la proliferación de los diarios y revistas digitales que cada vez ganan más lectores frente a los periódicos tradicionales en papel. De hecho, las principales cabeceras cuentan con ediciones digitales en una clara apuesta por ganar lectores. En este sentido cabe destacar que "la mayoría de las cabeceras que se editan en los países desarrollados, a pesar de mejorar la presentación y ensayar nuevas fórmulas informativas, han perdido difusión y credibilidad, lo que ha provocado un salto adelante en sus estrategias de diversificación en el hiper sector de la comunicación, con la revisión de sus ediciones en línea" (López García y Pereira Fariña, 2008: 180). Canarias no es ajena a este fenómeno y, por ello, los medios de comunicación digitales han aumentado de forma exponencial en el Archipiélago en los últimos años. De esta forma, además de las versiones digitales de las principales cabeceras de las islas, ha irrumpido en el panorama comunicativo un buen número de periódicos on line que han nacido con una clara vocación digital.

Sin embargo, no todos los medios que se puede consultar por Internet y que se denominan "diarios digitales" responden a los parámetros que debe tener un periódico on line y, por ello, en esta ponencia trataremos de establecer una diferencia clara entre los periódicos digitales existentes en Canarias y otros medios.

Por tanto este trabajo se basa en los periódicos digitales de información general de los que se aporta datos por islas, así como indicadores de seguimiento por parte de los lectores. También analizaremos los contenidos de los medios digitales más destacados, además de su línea editorial y sus rutinas de trabajo. 


\section{Metodología}

La aparición de los medios de comunicación digitales conlleva una modificación en las rutinas de la práctica periodística que deben adaptarse a un nuevo canal de comunicación interactivo y multimedia. Esto supone que los profesionales del periodismo deben aprender una nueva forma de presentar, estructurar y difundir las noticias que permita aprovechar al máximo las herramientas con las que cuenta la $\operatorname{Red}^{1}$.

El ámbito de la comunicación de las Islas Canarias se ha visto contagiado de las nuevas tendencias y se conforma como un escenario en el que han surgido en los últimos años numerosas publicaciones de ámbito regional e insular que inundan la Internet. Por un lado, estarían las versiones digitales de los medios tradicionales, que aunque no son el objeto de este estudio, se tendrán en cuenta a la hora de analizar el índice de audiencia y establecer datos comparativos con los medios digitales per se. Y por otro, éstos últimos que son la base de la presente investigación.

Los diarios digitales de información general en los que se centra este trabajo serían aquéllas publicaciones digitales sin referente fuera de Internet que constituyen un medio de información general de cobertura insular y regional, además de nacional e internacional en algunos casos también. Se trataría por tanto de diarios que nacen con el objetivo de constituirse en claros competidores de los periódicos impresos de referencia en las Islas Canarias.

Todos ellos se caracterizan por ofrecer información actualizada diariamente y por poseer una línea editorial que manifiestan explícitamente sobre temas de la actualidad de las islas, con carácter prioritario, y nacional por extensión, además de contar con numerosas firmas de opinión. La mezcla entre información y opinión varía en cada caso pero se encuentra presente en todos ellos.

\footnotetext{
${ }^{1}$ Una de las novedades más importantes que presentan estos medios es la integración de distintos formatos (texto, imagen fija, audio y vídeo) bajo un mismo soporte digital; característica que se ha denominado multimedialidad.
} 
Estos medios se erigen en canales que buscan tener la misma influencia que los medios tradicionales impresos y, en algunos casos, se constituyen ya en realidades empresariales consolidadas.

Dada la fragmentación espacial de las Islas Canarias, en este estudio se presentan datos generales de todos los diarios digitales existentes por islas, mientras que se analizará con detalle cinco publicaciones: canariasahora.es, el diario digital más seguido en Canarias y que se edita en Gran Canaria; Canarias24horas, una cabecera de carácter regional que se edita en Tenerife; canariaSocial, por su temática y línea destinada a difundir informaciones de una amplia variedad de colectivos tradicionalmente marginados; eldigitadecanarias.net, un diario de referencia para temas municipales e insulares y Tribuna de Canarias.es, que pertenece al Grupo Índice editor de otros diarios del mismo cariz.

Por lo que se refiere a estos cinco diarios on line a lo largo de esta ponencia se explicará cómo presentan las informaciones a los lectores, las secciones en las que distribuyen las noticias y su línea editorial.

Para realizar el estudio y obtener datos de audiencia y seguimiento se ha recurrido a fuentes de medición con una clara solvencia como son, por un lado, la OJD-Interactiva ${ }^{2}$, el Estudio General de Medios $(E G M)^{3}$, la empresa Nielsen Retratings ${ }^{4}$, una empresa auditora que realiza estudios de medición en Internet a nivel mundial, y el estudio de Audiencia sobre medios digitales realizado por la empresa Endesa. Asimismo se ha tenido en cuenta las

\footnotetext{
${ }^{2}$ La Ojd-Interactiva es la división de Información y Control de Publicaciones, S.A., que se encarga de prestar un servicio de certificación de la audiencia y difusión de los medios de comunicación en Internet. Más información en: <http://www.ojdinteractiva.es/acerca de la ojd.php> (Consulta: 15/08/2012).

3 El EGM ofrece datos de audiencias cada tres meses, pero sólo de medios que solicitan ser auditados y son aceptados. Tampoco incluye a los medios digitales que no participan en sus encuestas.

${ }^{4}$ La empresa Nielsen ofrece información de mercados integrada recopilada de una gran variedad de fuentes, avanzadas herramientas de gestión de la información, sofisticados sistemas y metodologías de análisis junto con un servicio profesional personalizado, para que los clientes encuentren el mejor camino hacia el crecimiento. Más información en: $<$ http://es.nielsen.com/company/what.shtml> (Consulta: 15/08/2012).
} 
mediciones realizadas por la herramienta Alexa ${ }^{5}$. Se da la circunstancia de que no todos los medios digitales canarios son auditados por la OJD-Interactiva o por el EGM de ahí que se haya tenido que consultar varios instrumentos de medición para obtener datos de algunos de ellos.

\section{Análisis}

\subsection{Distribución de cabeceras por islas}

Como se ha indicado anteriormente, la realidad fragmentada de las Islas Canarias ha generado la aparición de medios de comunicación de carácter insular y regional. Sin embargo, no todos ellos responden a las características que debe tener un diario digital de información general. Algunos se presentan como foros para el ejercicio del Periodismo Ciudadano, otros son meras guías de información turística y otros recuerdan la estructura y planteamiento de los blog. Además de los diarios digitales también se puede consultar revistas on line. En las tablas siguientes se ha hecho una distinción entre periódicos digitales y otros medios con el objeto de acotar y distinguir los distintos ámbitos en los que se dividen las publicaciones que actualmente se editan en las islas.

Cabe destacar también el hecho de que se ha reducido el número de cabeceras, bien por la desaparición de algunos medios -es el caso de Canariasaldia.com que cerró en octubre de 2011- o bien por su integración en otros -como Fuerteventuradigital- debido a la crisis económica que afecta a todos los sectores de la sociedad y que, en este ámbito, supone un

\footnotetext{
${ }^{5}$ Alexa Internet, Inc. es una subsidiaria de la compañía Amazon.com con base en California. Es conocida por operar el sitio web alexa.com que provee información acerca de la cantidad de visitas que recibe un sitio web y los clasifica en un ranking. Alexa recoge información de los usuarios que tienen instalado Alexa Toolbar, lo cual le permite generar estadísticas acerca de la cantidad de visitas y de los enlaces relacionados. Alexa también proporciona una gráfica donde se puede apreciar perfectamente el crecimiento/decrecimiento de las visitas a una página web, además de la información diaria (solo las 100.000 primeras páginas de la clasificación), media semanal y media de los últimos tres meses. Más información en: <http://www.alexa.com/> (Consulta: 15/08/2012)
} 
descenso importante en los ingresos provenientes de la publicidad, lo que ha impedido el mantenimiento de las redacciones de algunos periódicos.

En muchos casos se da la circunstancia de que algunos de estos proyectos comunicativos están dirigidos por periodistas que han desarrollado su carrera profesional en los periódicos tradicionales y que, tras encontrarse en el paro por los despidos que afectan al sector, han puesto en marcha estas iniciativas con el objeto de plantear alternativas serias a los periódicos en papel que permitan dar una mayor cobertura a la realidad de dichas islas. En las llamadas Islas menores sería el caso de elapuron.com el Periódico digital de La Palma.

Esta circunstancia responde a la realidad que están experimentando los medios de comunicación de hoy en día que, como se ha indicado anteriormente, ha supuesto un reto para los profesionales del periodismo que han tenido que adaptarse a nuevas rutinas y prácticas en la producción de los contenidos informativos.

En este sentido, según Cabrera (2004: 397)

"para la edición on line, el redactor debe estar dotado de unos conocimientos mínimos en tecnología informática, en los programas de edición de textos, imágenes en movimiento o video, etc. Con la prensa on line nace un nuevo periodista con formación redaccional y audiovisual".

\begin{tabular}{|c|c|c|}
\hline ISLA & CABECERA & CONTENIDOS \\
\hline \multirow[t]{2}{*}{ Fuerteventura } & Fuerteventuradigital & $\begin{array}{l}\text { Se integró en Noticanarias en abril de } \\
\text { este año. }\end{array}$ \\
\hline & $\begin{array}{l}\text { másFuerteventura.com } \\
\text { \& Illdósuêtleyentura.com }\end{array}$ & $\begin{array}{l}\text { Diario digital con contenidos insulares, } \\
\text { regionales, } \quad \text { nacionales } \\
\text { internacionales. }\end{array}$ \\
\hline \multirow[t]{2}{*}{ Lanzarote } & DiariodeLanzarote.com & $\begin{array}{l}\text { Diario digital sobre información } \\
\text { exclusivamente local de la isla de } \\
\text { Lanzarote. }\end{array}$ \\
\hline & Lanzarotedigital.com & $\begin{array}{l}\text { Diario digital que difunde la actualidad } \\
\text { solamente de la isla de Lanzarote. }\end{array}$ \\
\hline Gran Canaria & canariasahora.es & $\begin{array}{l}\text { Diario digital con un importante } \\
\text { seguimiento por parte de la audiencia } \\
\text { que difunde la actualidad regional, }\end{array}$ \\
\hline
\end{tabular}




\begin{tabular}{|c|c|c|}
\hline & canariasahora.es & nacional e internacional. \\
\hline & CanariasAIDia.com & Desapareció en octubre de 2011. \\
\hline & elindependientedeCanarias.com & Diario digital con contenidos de \\
\hline & & $\begin{array}{l}\text { carácter insular, regional, nacional e } \\
\text { internacional. }\end{array}$ \\
\hline & canariaSocial.com & $\begin{array}{l}\text { Diario digital que da voz a colectivos } \\
\text { del Tercer Sector, además de difundir } \\
\text { la actualidad de las islas. }\end{array}$ \\
\hline & $\begin{array}{ll}\text { La } & \text { Expresión } \\
\text { MaspalomasAhora.com } & \end{array}$ & $\begin{array}{l}\text { Diario digital fundado en } 2006 \text { con el } \\
\text { objetivo de informar sobre hechos } \\
\text { ocurridos en la comarca sur de Gran } \\
\text { Canaria. }\end{array}$ \\
\hline & Infonortedigital.com & $\begin{array}{l}\text { Diario digital con información } \\
\text { básicamente del norte de Gran } \\
\text { Canaria que nace con el objetivo de } \\
\text { contribuir al desarrollo de los } \\
\text { municipios de la zona. }\end{array}$ \\
\hline & $\begin{array}{l}\text { TeldeActualidad.com } \\
\text { TeldeActualidad.com }\end{array}$ & $\begin{array}{l}\text { Diario digital de información local de } \\
\text { Telde. }\end{array}$ \\
\hline Tenerife & LaTribunadeCanarias.com & $\begin{array}{l}\text { Periódico digital de las siete islas que } \\
\text { difunde información regional, nacional } \\
\text { e internacional. }\end{array}$ \\
\hline & 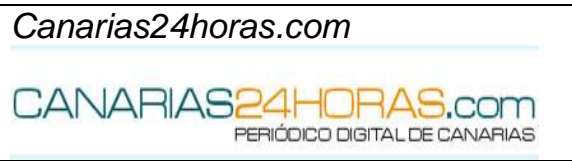 & $\begin{array}{l}\text { Diario digital con información regional, } \\
\text { nacional e internacional. }\end{array}$ \\
\hline & canarias-semanal.com & $\begin{array}{l}\text { Diario digital que ofrece información } \\
\text { regional, nacional e internacional. }\end{array}$ \\
\hline & $\begin{array}{l}\text { Tribuna de Canarias.es/Tribuna de } \\
\text { La Laguna }\end{array}$ & $\begin{array}{l}\text { Diario digital de información regional, } \\
\text { nacional e internacional. }\end{array}$ \\
\hline La Gomera & GomeraVerde.com & $\begin{array}{l}\text { Diario digital con información insular, } \\
\text { regional, nacional e internacional. }\end{array}$ \\
\hline & 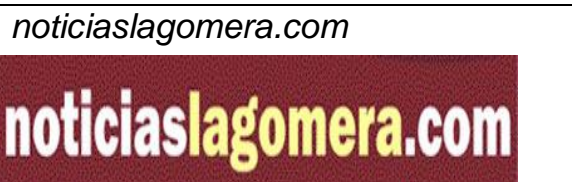 & $\begin{array}{l}\text { Diario digital que comenzó su } \\
\text { andadura el } 7 \text { de agosto de } 2007 \text { y } \\
\text { que ofrece información insular, } \\
\text { regional, nacional e internacional. }\end{array}$ \\
\hline
\end{tabular}

Facultad de Ciencias de la Información - Universidad de La Laguna

Avenida César Manrique, s/n; Campus de Guajara

38071 La Laguna, Tenerife (Islas Canarias - España) 


\begin{tabular}{|l|l|l|}
\hline La Palma & elapuron.com & $\begin{array}{l}\text { Diario digital con contenidos } \\
\text { exclusivamente de la actualidad de la } \\
\text { isla de La Palma. }\end{array}$ \\
\cline { 2 - 3 } & LavozdeLaPalma.com & $\begin{array}{l}\text { Diario digital que difunde la actualidad } \\
\text { palmera, cuenta con un apartado } \\
\text { sobre ecología. Destaca la cobertura a } \\
\text { los acontecimientos deportivos. }\end{array}$ \\
\cline { 2 - 3 } & LaPalmaenlinea.com & $\begin{array}{l}\text { Diario digital en el que se da cobertura } \\
\text { sobre todo a la información municipal } \\
\text { de la isla de La Palma. }\end{array}$ \\
\hline El Hierro & $\begin{array}{l}\text { Diario sobre actualidad de El Hierro y } \\
\text { de las islas Canarias a través del } \\
\text { apartado 'El Gobierno informa'. Llama } \\
\text { la atención la sección denominada } \\
\text { Portal Canario-Cubano. }\end{array}$ \\
\hline
\end{tabular}

Tabla 1: En esta tabla se recogen los diarios digitales informativos de todas las islas

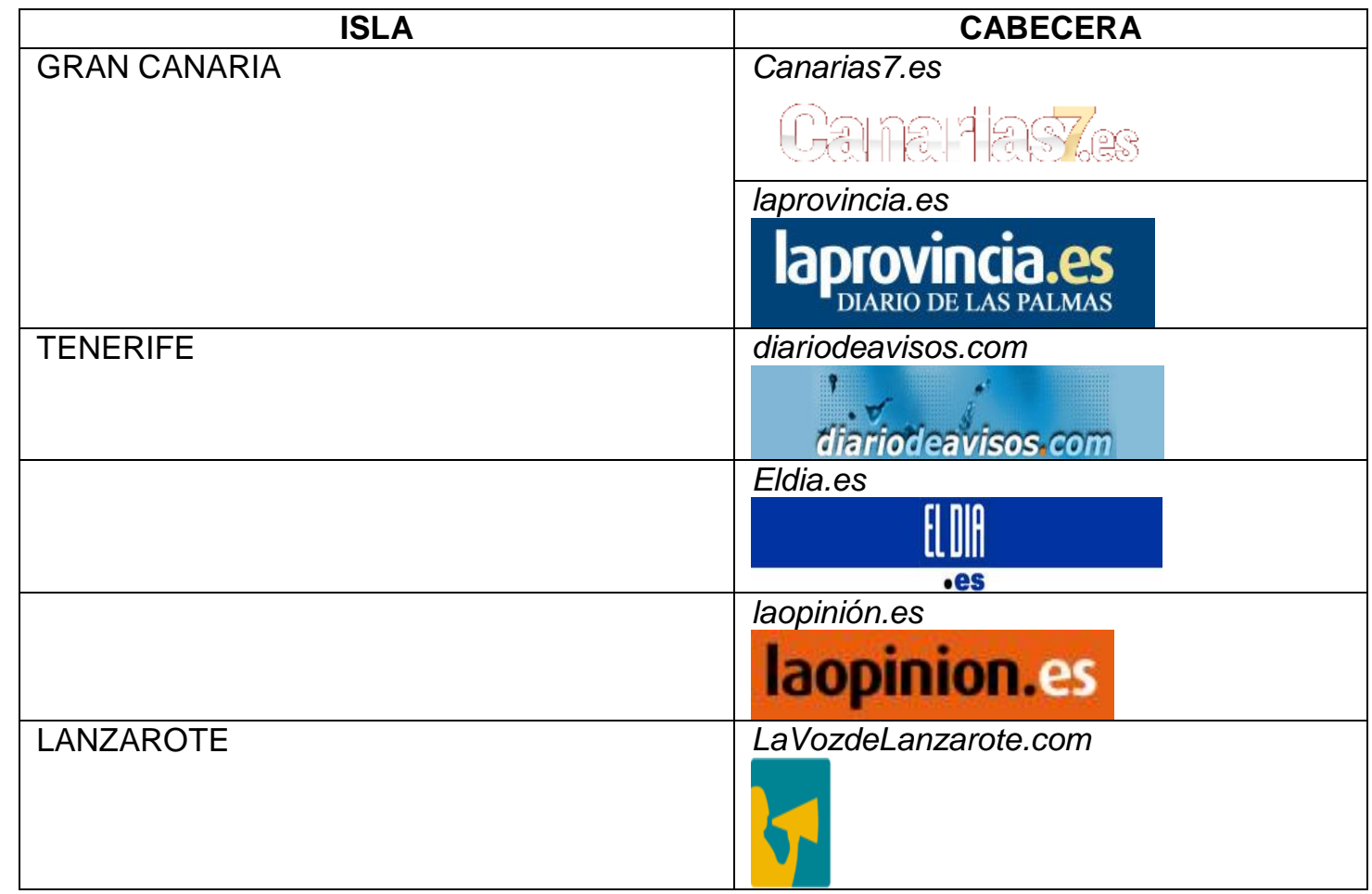

Tabla 2: Versiones digitales de las principales cabeceras de las islas 


\begin{tabular}{|l|l|}
\hline LaRevistadeLaPalma.com & $\begin{array}{l}\text { Revista que ofrece información general } \\
\text { pero también sobre ocio y cultura, } \\
\text { deportes, empleo y tendencias. }\end{array}$ \\
\hline CulturaTenerife.net & $\begin{array}{l}\text { Revista con contenidos puramente } \\
\text { culturales referidos a la isla de Tenerife. }\end{array}$ \\
\hline BienMeSabe.org & $\begin{array}{l}\text { Revista digital de cultura popular } \\
\text { canaria. }\end{array}$ \\
\hline Tara.com & $\begin{array}{l}\text { Revista digital de información general } \\
\text { básicamente con contenidos de la } \\
\text { provincia de Las Palmas. }\end{array}$ \\
\hline
\end{tabular}

Tabla 3: Revistas digitales de las Islas

Algunos ejemplos de medios que se dedican al llamado Periodismo Ciudadano en las islas son: loquepasaenTenerife.com, ArchipiélagoNoticias.com y LaPalmaprotesta.com, en todos ellos los ciudadanos envían comentarios sobre lo que ocurre en su realidad más próxima.

De la información recogida en las tablas anteriores se detrae que la isla de Gran Canaria abandera la creación de medios digitales en el Archipiélago, mientras que la otra isla capitalina, es decir Tenerife se encuentra algo por detrás. También se constata que todas las islas sin excepción cuentan con algún diario digital de información diaria.

Destaca también el hecho de que en la isla de Gran Canaria distintas comarcas y municipios cuentan con su propio diario de información on line con contenidos especializados en esas áreas y además algunos de ellos se consideren como un elemento que favorece el desarrollo de estas zonas. 


\subsection{Estudio de las cabeceras más importantes}

\subsection{1. canariasahora.es}

\section{canariasahora}

Imagen 1

canariasahora.es es el periódico digital canario que cuenta con un mayor índice de seguimiento entre el público de las islas. La última oleada de la Ojd-Interactiva muestra que el diario alcanzó en el mes de julio de este año un total de 131.010 usuarios, lo que supone un $2,56 \%$ de incremento.

Este periódico, que nació con una clara vocación digital en el año 2000, tiene como uno de sus principios básicos según se explica en su portal, proponer "a nuestros lectores un pacto consistente básicamente en no callar nunca, decir toda la verdad, y explicar y diseccionar el sistema en cada ocasión cuando la importancia de los asuntos lo requiera”.

Su objetivo es hacer de la credibilidad el principal valor del periódico, por ello sus editores, el Grupo Canarias Ahora, se han empeñado en limitar al máximo los campos vedados, porque “cuanto más amplios sean éstos, más rápidamente se perderá la confianza del lector”.

En cuanto a su línea editorial, este medio apuesta por la "decencia" y se declara al margen de cualquier partido político, pues no se considera representado por ninguno. Es más, se compromete con los lectores a contar "todo lo bueno y todo lo malo de las propuestas realizadas por cada formación política".

canariasahora.es es un diario digital de información general en sentido estricto, dirigido por Carlos Sosa, que, como se ha indicado, presenta una clara línea editorial comprometida con los lectores de las islas, y que ofrece contenidos diariamente actualizados de carácter insular, regional, nacional e internacional.

\footnotetext{
${ }^{6}$ Más información en: <http://www.canariasahora.com/nosotros/> (Consulta: 13/07/2012).
} 
Este medio cuenta con una serie de secciones fijas entre las que destaca 'Top Secret'. En este apartado se ofrecen informaciones, muchas veces con un claro matiz editorializante, en las que se mezcla información y opinión para denunciar casos de corrupción, irregularidades y fallos en la gestión de los poderes públicos y de los políticos que causan perjuicios a los ciudadanos. Cada una de las entradas cuenta con un antetítulo, titular, el texto y una foto, aunque ésta última sólo en algunos casos.

Otros apartados destinados a la información, reproduciendo las secciones que normalmente contienen los diarios en papel, son: Canarias, Nacional, Internacional, Economía, Deportes, Sociedad, Diversia, Cultura, Tecnología y Radio. Cada una de las islas tiene su propio espacio con información local. También hay una sección de Opinión con numerosas firmas reconocidas.

Por lo que respecta a la presentación de las informaciones, en la Portada, tras la cabecera, aparecen las secciones y un pequeño apartado denominado 'Noticias del día' en el que se ofrecen los titulares de los hechos que ocurren durante la jornada indicando la hora en la que se producen.

Según Luis Albornoz (2007: 56), la actualización permanente de los contenidos informativos de los periódicos on line "es sin duda una opción que permite a las editoras competir informativamente con medios que responden a un modelo de flujo como son la radio y la televisión. Algunos medios on line suelen indicar el horario en que actualizan su página de inicio o portada e indicar el horario en que cada noticia fue publicada, lo cual permite que los lectores puedan percibir y seguir el flujo informativo cronológicamente".

La página se parcela en tres partes que funcionan a modo de columnas en las cuales se distribuyen las informaciones. La noticia destacada de la Portada se presenta a dos columnas con un titular, antetítulo y una entradilla. El resto va a una columna.

Al final de la página hay una franja denominada 'Más noticias' con titulares sobre noticias pertenecientes a los apartados de Canarias, Sociedad y Nacional. 
Por lo que respecta a las secciones, llama la atención que la información de apertura de cada una de ellas vaya en un recuadro de color, diferente según la sección, en el que se ofrece un titular que remite, una vez que se cliquea sobre el mismo, al texto completo de la noticia. En estas páginas las informaciones van a dos columnas. Normalmente las noticias se presentan con la firma del autor, que puede ser Redacción o Agencias, la fecha y la hora. Un antetítulo precede al titular y suele haber también un subtítulo. Al final el lector tiene la posibilidad de incluir comentarios sobre el contenido. Esto supone que, frente al receptor de los medios tradicionales en papel, el lector de medios digitales se convierte en un elemento activo del proceso de comunicación ya que con su participación puede llegar a influir en los contenidos informativos.

En las secciones dedicadas a la información insular, las noticias se distribuyen en dos columnas. En el caso de Fuerteventura cabe destacar que la página web remite al lector al diario Fuerteventuraahora, el primer diario digital nacido en la isla majorera.

Por su parte, el apartado Diversia lleva al público a la Agenda y revista cultural de Canarias del mismo nombre. En dicha página existen a su vez varios apartados que son: Inicio, Agenda, Noticias, dónde ir y tú recomiendas.

\subsubsection{Canarias24horas.com}

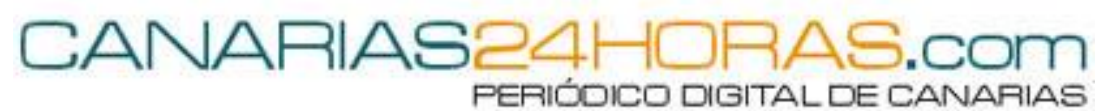

Imagen 2

Canarias24horas.com es un diario digital, editado en Tenerife desde el año 2005, que cuenta con un equipo numeroso de redactores que se encuentran presentes en cada una de las siete islas que conforman el Archipiélago Canario. Este diario tiene como objetivo 
proporcionar información veraz, contrastada y de primera mano sobre todo lo que acontece en los diversos municipios de las islas. Además se propone tratar por igual a las siete islas.

Este medio se declara libre de intereses que no sean el puro y más estricto deber de ofrecer información contrastada, teniendo como premisa la defensa de los intereses de sus lectores por lo que se trabajará para ofrecer informaciones veraces, actuales, completas y de calidad, donde se diferenciará la opinión de los otros géneros periodísticos ${ }^{7}$. Para lograr una contextualización de los hechos en su grado máximo, Canarias24horas hace uso del hipertexto ${ }^{8}$ enlazando sus contenidos con otros sitios web que puedan ser de utilidad al lector a la hora de aumentar sus conocimientos sobre un tema.

El periódico estructura sus contenidos en las siguientes secciones: una Portada que hace la función de Primera página; Canarias, Economía, Política, Sociedad, Deportes, Cultura, Videos, Nacional e Internacional. Además hay un apartado destinado a cada una de las islas, en correspondencia con la filosofía del medio de dar un tratamiento igualitario a todas las islas del Archipiélago. También cuenta con una sección para la Opinión.

En la Portada, tras las secciones, aparece un apartado denominado 'Te interesa' en un recuadro naranja que da paso a los titulares del día. En cuanto a la presentación de las informaciones, la noticia de apertura se edita dentro de un recuadro con un titular en letra naranja. La utilización de este color, que se emplea en la cabecera, produce un impacto claro en el lector con lo que cumple la función de alertar sobre la importancia de la información que se ha elegido como más destacada del día.

La primera página cuenta también con una columna de 'Titulares destacados'. La página se parcela en tres columnas en las que se presentan las distintas entradas. Normalmente las dos primeras contienen sólo información y en la tercera se insertan, además, comentarios y artículos de opinión.

\footnotetext{
${ }^{7}$ Más información en: <http://www.canarias24horas.com/quienes-somos> (Consulta: 15/07/2012).

${ }^{8}$ La hipertextualidad es una forma multidireccional, no lineal, de estructurar y acceder a la información en los entornos digitales a través de enlaces.
} 
Al final de la página hay dos recuadros con titulares de las secciones Nacional e Internacional y un apartado con titulares sobre tres ámbitos: Últimas noticias, Lo más leído y Lo mejor de la semana.

Cada sección presenta las informaciones ordenadas en función de los días en los que se producen, y la fecha en la que ocurrieron se indica en un recuadro en tonos naranja con el número, reproduciendo el diseño de las agendas al uso. Cada noticia se edita con un titular, la firma del autor que puede ser Redacción o Agencias, normalmente Europa Press y Acn Press, y una llamada a la sección en la que se publica, además de una foto que da paso al texto. Cada entrada va separada por una línea en tono naranja. Al igual que ocurría con el diario reseñado anteriormente los lectores tienen la posibilidad de insertar comentarios en cada noticia.

Por lo que respecta a los apartados destinados a cada una de las Islas, las de Tenerife y Gran Canaria están divididas a su vez en Santa Cruz de Tenerife, Tenerife Sur y Tenerife Norte, en el primer caso, y Las Palmas, Gran Canaria Sur y Gran Canaria Norte, en el segundo. Cada noticia aparece con un titular, la firma, Publicado en, una foto y el texto.

\subsection{3. canariaSocial.com}

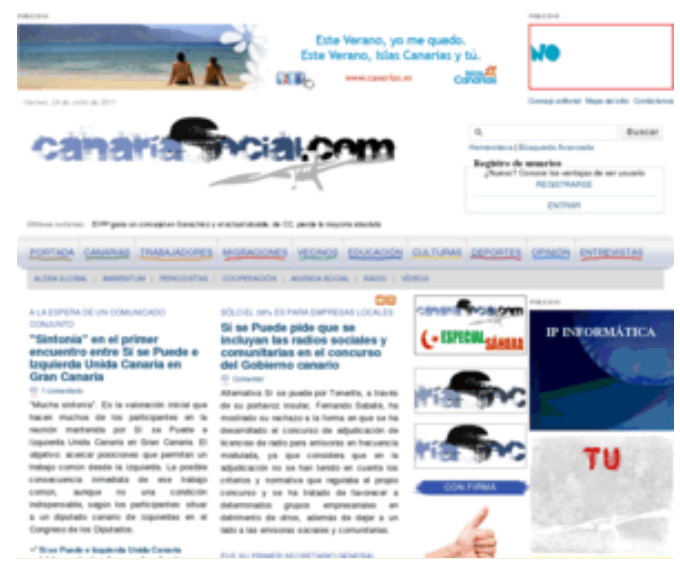

Imagen 3 
El Archipiélago canario también cuenta con ejemplos de medios de comunicación digitales preocupados por difundir la realidad que viven los distintos colectivos sociales de las islas, y un claro ejemplo de ello es canariaSocial.com. La empresa editora de este diario es Mafeking $^{9}$ y cuenta con un Consejo Editorial ${ }^{10}$ que tiene carácter rotatorio en el que participan varios colectivos sociales. Dicho Consejo sirve de apoyo a la labor informativa desarrollada por este medio y, según se recoge en su página web, "nos ayuda a buscar nuevas miradas en Canarias y su sociedad"11.

El periódico cuenta con las siguientes secciones: Canarias, Trabajadores, Migraciones, Vecinos, Educación, Culturas, Deportes, Opinión, Entrevistas, Aldea Global, Ambientum, Periodistas, Cooperación, Agenda Social, Sanidad, Política y Economía. También ofrece información del tiempo.

Por lo que se refiere a los contenidos de las secciones indicadas, los lectores pueden encontrar en cada una de ellas información sobre los siguientes temas:

- Canarias: Difunde los temas de interés para los habitantes del Archipiélago canario.

- Trabajadores: Noticias sobre el ámbito laboral, sindicatos, protestas, accidentes laborales, pérdida de empleo y situación del mercado laboral en general.

- Migraciones: Cuestiones relacionadas con la inmigración y el empleo, la actividad de las asociaciones de inmigrantes, el acoso que sufren y el arraigo social.

- Vecinos: Actividad de las plataformas vecinales, y actualidad municipal en las islas.

\footnotetext{
9 Mafeking es una sociedad civil particular, cuyo objeto social consiste en la realización de actividades editoriales, informativas y culturales en general y producción audiovisual, así como actividades de carácter social y de cooperación al desarrollo. Inició su actividad el 17 de octubre de 2008, inscrita en el Registro de Entidades Jurídicas del Ministerio de Economía y Hacienda con CIF 576012335. Más información en: <http://www.canariassocial.com/aviso-legal> (Consulta: 12/03/2012).

${ }^{10}$ En la actualidad, el Consejo Editorial de Canarias Social está integrado por Comisiones Obreras Canarias, la Asociación de Jóvenes Saharauis de Canarias, Ben Magec-Ecologistas en Acción, y la Asociación para la Recuperación de la Memoria Histórica y el del municipio de San Lorenzo.

${ }^{11}$ Más información en: <http://www.canariassocial.com/consejo-editorial?tmpl=component\&print=1\&page> (Consulta: 12/03/2012).
} 
- Educación: Convocatoria de exámenes y oposiciones, desarrollo de proyectos educativos, la Universidad y su entorno y desarrollo de iniciativas de relacionadas con el campo de la investigación.

- Culturas: Información relativa a diversas manifestaciones culturales.

Además, cada isla cuenta con una sección propia en la que se difunde la actualidad que transcurre en su ámbito territorial.

En cuanto a la distribución de las informaciones, tras la cabecera hay una entrada con los titulares de las Últimas noticias y las denominaciones de las distintas secciones que dan paso a los contenidos colocados en cuatro columnas con el reparto siguiente: las informaciones van en la columna de la izquierda y central izquierda, la opinión en una pequeña columna en el centro derecha y la publicidad en la de la derecha.

Cada información se presenta con un antetítulo, un titular y la entradilla. En algunos casos hay fotografías que acompañan al texto. Los lectores tienen la posibilidad de insertar comentarios sobre las noticias.

En el apartado denominado 'Periodistas' se ofrece información vinculada al mundo del periodismo, que abarca desde presentaciones de libros y conferencias, a notas vinculadas con los medios, nuevas iniciativas, plataformas, etc.

'Ambientum' es el espacio que dedica este medio de comunicación a la difusión de las informaciones relacionadas con cuestiones medioambientales, la ecología y la conservación y preservación del entorno natural de las islas. Se presta especial atención a temas de actualidad, como la tercera pista del Aeropuerto de Gando en Gran Canaria o la construcción del Puerto de Granadilla, en Tenerife, asuntos ambos que han provocado un amplio y controvertido debate en las islas en la última década.

En el apartado 'Aldea Global', los lectores pueden encontrar múltiples noticias sobre el conflicto saharaui; la actividad de Amnistía Internacional; la situación de los países del Magreb a raíz de los recientes conflictos vividos, como es el caso de Libia; el conflicto 
israelo-palestino, las manifestaciones de las organizaciones pacifistas y acontecimientos relacionados con países del África negra, como Senegal y Gambia.

'Cooperación' difunde las actividades de las Organizaciones No Gubernamentales, iniciativas vinculadas a la cooperación al desarrollo, movilizaciones contra la exclusión social y en apoyo de colectivos en riesgo y proyectos de solidaridad.

Según una información ${ }^{12}$ publicada por este diario digital, canariaSocial.com obtuvo sus mejores resultados por lo que se refiere a la difusión el pasado mes de noviembre de 2011 con 7.615 usuarios únicos, que consultaron un total de 17.373 páginas. Son los mejores datos cuantitativos obtenidos por este medio desde su nacimiento hace algo más de dos años.

\subsection{4. eldigitaldecanarias.net}

\section{eldipitaldecanarias net}

Imagen 4

eldigitaldecanarias.net es una nueva aventura dentro de la prensa digital hecha desde Canarias para los canarios y asume el compromiso de traer a todos sus habitantes una forma distinta de hacer noticias y entenderlas, siempre dentro del compromiso de informar verazmente a todos sus lectores. Su objetivo, según explican, es "abrir una ventana de información auténticamente libre, sin ataduras, ya que ni queremos enriquecernos ni

12 Véase la página web: <http://www.canariassocial.com/portada/periodistas/item/14331-canarias-social-alcanza-susmejores-datos-en-noviembre> (Consulta: 20/02/2012). 
tampoco queremos formar parte de ningún entramado político o empresarial que nos use para atender sus intereses" ${ }^{\prime 13}$.

Este medio hace una apuesta clara por difundir las informaciones que suceden en el Archipiélago, aspecto que se plasma claramente en las distintas secciones en las que estructura sus contenidos. Cabe destacar la importancia que se da a los contenidos relacionados con la realidad que viven día a día los municipios de las islas.

De esta forma en su Portada se anuncian las siguientes secciones: Tenerife, Gran Canaria, Islas, Municipios, Cultura, Deportes, Economía, Sociedad, Sucesos, Política, El Tiempo y Artículos.

Por lo que respecta a la estructura de la página, los contenidos se distribuyen en tres columnas, de las que la de la izquierda y central están dedicadas exclusivamente a difundir noticias, mientras que en la derecha se incluye la publicidad, se anuncian los artículos de opinión y se ofrece una galería de fotografías.

En la Portada, cada información aparece con la indicación de la sección en la que se puede leer, el titular, una foto y un subtítulo. Al final de la página hay una apartado en el que se resumen los titulares más destacados de cada una de las secciones. También hay un enlace con el diario másFuerteventura.com.

Por su parte, cada sección ofrece una relación de las informaciones del día, cada una con un titular y un subtítulo que dan paso al texto completo. La noticia aparece además con la fecha y hora en la que se produce y al final el lector puede hacer los comentarios que estime oportunos al igual que ocurría en el caso de los dos diarios anteriores.

\footnotetext{
${ }^{13}$ Más información en: <http://www.eldigitaldecanarias.net/html.php?idh=2> (Consulta: 25/07/2012).
} 


\subsubsection{Tribuna de Canarias.es}

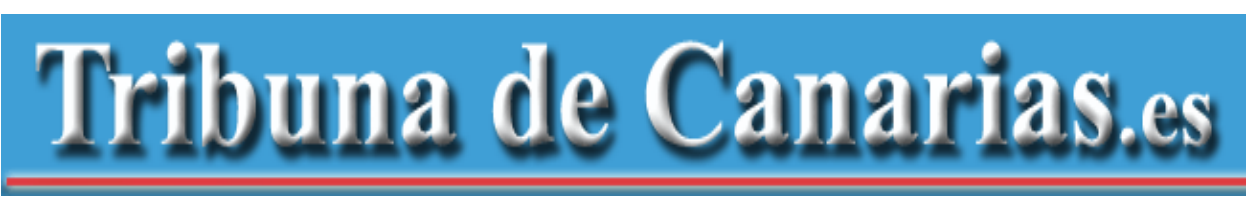

Imagen 5

Este diario pertenece al Grupo Índice Comunicación ${ }^{14}$ en el que se integran otros medios repartidos por toda la geografía del país bajo el epígrafe de "Tribuna de....", en correspondencia con el ámbito geográfico en el que se editan. Se trata de un diario digital de información general que distribuye sus contenidos en las siguientes secciones: Economía, Política, Internacional, Nacional, Sociedad, Cultura, Deportes, Canarias, Tribuna de La Laguna, Opinión, Editorial, Tecnología, Reportajes, Última Hora, Milenio y Gente. También dedica apartados específicos a la cobertura de las noticias que ocurren en cada una de las islas.

La página se estructura en tres columnas en las que se distribuyen las informaciones. Cada una de las entradas se presenta con un titular en letras azules y un pequeño texto a modo de entradilla que invita a la audiencia a leer el resto de la noticia. En algunos casos, los menos, el texto va acompañado de una foto.

En esta Primera Página, mientras que las columnas de la izquierda y central se destinan a la edición de las informaciones, sin diferenciar la sección o ámbito al que corresponden, en la columna de la derecha, se incluyen algunos contenidos de Tribuna de La Laguna como una llamada para atraer al lector a este otro medio asociado.

El hecho de que en esta Primera Página no se indique a qué sección corresponden las noticias dificulta que el lector pueda saber en qué ámbito se producen las mismas y a qué

\footnotetext{
${ }^{14}$ Este grupo se especializa en el manejo de Relaciones Públicas, monitoreo de medios y asesoría en comunicación integrada y está presente en un buen número de países de habla hispana. Más información en: $<$ http://www.grupoindice.com/indicesomos.html> (Consulta: 13/08/2012).
} 
realidad se refieren. Además parece que las informaciones se colocan sin un orden de prioridad claro, es decir, no hay una noticia de apertura que pueda distinguirse claramente del resto.

Asimismo se ofrece algunos de los contenidos de las secciones destinadas a las Islas a través de los titulares de las informaciones y, en algunos casos, también del inicio del texto informativo. Además, hay espacios dedicados a la inserción de anuncios publicitarios y a los artículos que conforman la sección de opinión.

Por lo que respecta a las secciones, en cada una de ellas se ofrece una relación de titulares con la fecha y la referencia a la sección en la que están. Todas las noticias están firmadas por Redacción y aparecen dentro de un recuadro sin fotos. Resulta llamativo el hecho de que en este diario no se recurre a la fotografía, el vídeo o a otros elementos multimedia como sí ocurre en los casos anteriores. Al final de cada uno de los textos hay un anuncio publicitario. En este caso cabe destacar también el hecho de que, contrariamente a lo que ocurría con los medios estudiados en apartados precedentes, los lectores no tienen la posibilidad de insertar comentarios a las informaciones que se les ofrecen.

\subsection{Datos de Audiencia}

A pesar de la cantidad de medios con clara vocación y origen digital que existen en Canarias, los índices de audiencia muestran que los lectores de las Islas Canarias siguen mayoritariamente para informarse las versiones digitales de los periódicos en papel. Los datos más recientes publicados por la Oficina para la Justificación de la Difusión (OJD) correspondientes al mes de julio indican que la edición digital de Canarias7.es tuvo 62.772 visitantes únicos diarios, y un promedio de 761.590 mensuales, lo que supone un incremento del 7,26 por ciento y coloca a este medio en la cabeza de diarios digitales canarios. Por contra laprovincia.es bajó un 3,32 por ciento y obtuvo 46.034 visitantes únicos diarios y 638.292 de media mensual. Por su parte, eldía.es recibió 28.686 visitantes únicos diarios; 
diariodeavisos.com 21.275; laopinión.es 16.560 y canariasahora.com 13.032 visitantes únicos diarios.

Por lo que respecta a las páginas vistas elegidas por los lectores, durante el mes de julio, los lectores de Canarias7.es realizaron un total de 2.790 .629 visitas y recorrieron un total de 11.200.086 páginas; laprovincia.es obtuvo 8.795.765, eldia.es 3.240.773, diariodeavisos.com 2.112.390, laopinion.es 2.055.548, y, finalmente, canariasahora.com obtuvo 1.262.604 páginas vistas.

Por su parte, Canarias24horas recibió en el mes de julio un total de 104.547 visitas, que recorrieron un total de 979.180 páginas, según se refleja en los datos proporcionados por la dirección de este medio.

De esta forma, encontramos que, según datos recogidos en un estudio realizado por Endesa sobre Audiencia de Medios digitales en el mes de abril de este año ${ }^{15}$, el $67 \%$ de los lectores canarios eligió laprovincia.es, Canarias7.es y eldía.es para informarse, mientras que el 33\% restante se decantó por laopinión.es, diariodeavisos.com y canariasahora.com.

Del $67 \%$ ya mencionado, un 28\% correspondió a Canarias7.es, el 23\% a laprovincia.es; el $17 \%$ a eldía.es, el $10 \%$ a laopinión.es, el $11 \%$ a diariodeavisos.com y el $6 \%$ a canariasahora.com.

Por lo que respecta al volumen de lectores canarios de prensa on line, la empresa Nielsen España ${ }^{16}$, experta en medición de audiencias, ha establecido que en el Archipiélago hay más de 398.900 usuarios, mientras que en el conjunto del país son más de 14 millones, los internautas que eligen la Red como canal para estar al tanto de la actualidad.

Según esta empresa, Canarias figura entre las diez primeras Comunidades autónomas con más lectores de prensa on line, por delante de Madrid o Cataluña, aunque por detrás de otras como Extremadura o Asturias. Esto supone que el 61,5\% de los internautas canarios

15 Véase la página web: <http://www.slideshare.net/LASINICIATIVAS/audiencia-medios-digitales-canarias-abril12> (Consulta: 15/07/2012).

${ }^{16}$ Véase la página web: <http://canarias7.es/articulo.cfm?id=250758> (Consulta: 15/07/2012). 
elige la Red para mantenerse al día e informarse de la actualidad de su entorno. Estos resultados tan destacados se explican en parte porque Canarias ha experimentado en los últimos años un importante incremento en lo referente a la presencia de ordenadores personales en los hogares de las islas que cuentan con conexión a Internet y banda ancha. De esta forma, y siguiendo las cifras recogidas en la Encuesta sobre equipamiento y uso de TIC en los hogares de las islas en el año 2011 realizada por el INE ${ }^{17}$, la disponibilidad de equipamiento básico de TIC ha registrado una evolución del 4,5\% en los que se refiere a la disponibilidad de ordenador y superior al $6 \%$ en lo que respecta a la conexión a Internet y banda ancha.

Según esta encuesta, en el año 2011 el $70 \%$ de los hogares canarios con al menos un miembro de 16 a 74 años dispone de ordenador, frente al $67 \%$ de 2010 , mientras que el $76,7 \%$ tiene teléfono fijo(dos puntos porcentuales más que en el año anterior).

Por lo que respecta al acceso a Internet, el $62 \%$ de los hogares canarios dispone de conexión a la red, frente al $58,4 \%$ de 2010 . El porcentaje de viviendas con acceso de banda ancha asciende en 2011 al 60,5\%, casi cuatro puntos porcentuales más que el año anterior.

Por lo que se refiere al resto de comunidades, cabe destacar que País Vasco y Navarra encabezan la lista y se sitúan como las más activas a la hora de seguir la actualidad a través de la Red con el $67,1 \%$ y el $65,9 \%$.

Aunque se escapa del ámbito de estudio contemplado en esta ponencia, hemos incluido también datos sobre los diarios digitales nacionales más leídos en las islas de tal forma que en primer lugar se encuentra ELMUNDO.es, que con más de 139.000 usuarios únicos lo que supone un 21,1 por ciento, adelanta a ELPAÍS.com, que le sigue con 123.800 lectores, un 19,1 por ciento. A continuación se encuentra $A B C$.es, que con más de 122.000 usuarios al mes, concentra el 18,8 de la audiencia canaria de prensa digital.

\footnotetext{
${ }^{17}$ Más información en: <http://www.ine.es/prensa/np678.pdf s > (Consulta: 18/08/2012).
} 


\section{Conclusiones}

1. La mayoría de los diarios digitales canarios se presentan ante la audiencia como abanderados de la independencia del poder político y de las formaciones políticas, claramente en entredicho entre la opinión pública debido a los múltiples casos de corrupción y a la mala gestión realizada. Es una forma de diferenciarse de los diarios en papel vinculados a grupos políticos o empresariales.

2. Todas las islas cuentan con diarios digitales, lo que muestra que hay una conciencia clara de la necesidad de adaptarse a las nuevas formas de comunicar así como de explotar las posibilidades que ofrece la Internet.

3. La isla de Gran Canaria es la que tiene más diarios digitales de información diaria, medios que se adjudican el papel de impulsores del desarrollo de determinadas comarcas de la isla.

4. A pesar de la proliferación de medios digitales en Canarias, el público de las islas acude mayoritariamente para informarse a las versiones digitales de los periódicos tradicionales en papel.

5. Muchos de los proyectos informativos digitales están encabezados por periodistas con una larga trayectoria profesional en los periódicos, radios y televisiones de las islas que se han tenido que adaptar a una nueva forma de informar.

6. La mayoría de los diarios buscan la participación activa de los lectores en el proceso de comunicación a través de la inserción de comentarios en los textos.

7. La implantación cada vez mayor de las nuevas tecnologías en las islas y la presencia de ordenadores personales en muchos hogares ha permitido el acceso del público a los medios digitales de forma generalizada. 


\section{Bibliografía}

ALBORNOZ, L. A. (2007). Periodismo digital. Los grandes diarios en la Red. Buenos Aires:

La Crujía.

ALMIRON, N. (2006). "Pluralismo en Internet: el caso de los diarios digitales españoles de información general sin referente impreso", Ámbitos, nำ15, pp. 9-31.

ALMIRON, N. y JARQUE J.M. (2008). El mito digital. Discursos hegemónicos sobre Internet y periodismo. Barcelona: Rubí.

CABRERA, M. A. (2004). "Periodismo digital y nuevas tecnologías". En: Barrera C. (Coord.). Historia del Periodismo Universal. Barcelona: Ariel comunicación, pp. 393-417.

ENDESA (2012). "Audiencia medios digitales. Abril 2012" [en línea]. En: $<$ http://www.slideshare.net/LASINICIATIVAS/audiencia-medios-digitales-canariasabril12> (Consulta: 15/07/2012).

INE (2011). "Encuesta sobre equipamiento y uso de TIC en los hogares de Canarias" [en línea]. En: <http://www.ine.es/prensa/np678.pdf> (Consulta: 18/08/2012).

LACASA MAS, I., MAS M.V. y FERNANDEZ DIEZ, M. (2012). "Confianza en la marca periodística y adopción de la prensa on-line", Icono 14, Año 10, vol. 1, pp. 213-229.

LOPEZ GARCÍA, X. Y PEREIRA FARIÑA, X. (2008). "La prensa ante el reto on line. Entre las limitaciones del modelo tradicional y las incógnitas de su estrategia digital. En: Bustamante, E. Franquet, R., García Leyva, T., López, X. Y Pereira, X. Alternativas en los medios de comunicación digitales. Barcelona: Gedisa, pp. 177-244.

OBSERVATORIO NACIONAL DE LAS TELECOMUNICACIONES Y DE LA SOCIEDAD DE LA INFORMACIÓN (2011). "Informe anual de los contenidos digitales en España. Industria y hábitos de consumo. Año 2011" [en línea].En: $<$ http://www.ontsi.red.es/ontsi/sites/default/files/informe contenidos digitales 2011 v7.p df> (Consulta:18/08/2012) 


\section{Forma de citar este artículo en bibliografías}

ÁLVAREZ DÍAZ, Araceli (2013): "Los medios digitales en Canarias: una forma de comunicar que se impone a los canales tradicionales", en Revista PANGEA, 4, páginas 263 a 278. Red Académica Iberoamericana de Comunicación. Recuperado el _ de __ de 2 ___ de: http://revistapangea.org 